\title{
ÍNDICES DA ANÁLISE DE CRESCIMENTO EM FUNÇÃO DAS CONDIÇÕES DE CULTIVO DE AVEIA PRETA
}

\section{Claudia Antonia Vieira Rossetto ${ }^{1}$ \\ João Nakagawa ${ }^{2}$}

\section{RESUMO}

O objetivo do presente trabalho foi estudar o comportamento fisiológico de plantas de aveia preta (Avena strigosa Schber), cultivar Comum, submetidas a diferentes condições de cultivo, através da análise de crescimento. Para isto, foram instalados três experimentos, no mês de maio, em Terra Roxa Estruturada e em solo classificado como Solo Litólito, nos anos de 1986 e 1987, em Botucatu-SP. O delineamento experimental utilizado foi inteiramente casualizado, com três repetições. Os tratamentos, em número de 8,7 e 6 , constaram de épocas de coletas de plantas, iniciadas aos 21 dias após a emergência das plântulas, com intervalos de 21 dias. Para cada experimento, em cada época de coleta, as plantas foram levadas para o laboratório para avaliação da área foliar e para determinação da matéria seca das raízes, das hastes, do limbo e das bainhas das folhas, das sementes e das raques das panículas e, da matéria seca total, todos em $\mathrm{g} / \mathrm{m}^{2}$. Com estes dados $₫$ ram calculados os parâmetros físiológicos da análise de crescimento. As condições de cultivo causaram consideráveis diferenças entre experimentos nos valores de índice de área foliar, de duração de área foliar e de matéria seca total, com reflexos na taxa de crescimento relativo e na taxa de crescimento da cultura. Os três experimentos apresentaram similaridades nos padrões das curvas dos

1 Departamento de Fitotecnia, IA, UFRRJ, Cep: 23851-970, Seropédica-RJ.

2 Departamento de Produção Vegetal, FCA, UNESP, CEP:18603-970, Botucatu-SP. Com bolsa do CNPq. 
parâmetros fisiológicos no decorrer do desenvolvimento das plantas, apesar das diferenças de condições de cultivo.

Palavras-chave: Avena strigosa, análise de crescimento.

\section{ABSTRACT}

\section{INDEX GROWTH ANALYSIS IN BLACK OAT PLANTS (Avena strigosa)}

Three experiments were carried out in 1986 and 1987 in Botucatu, State of São Paulo, Brazil, to study, by growth analysis, the effect of crop conditions on Avena strigosa Schreb plants, cv. Comum. The experimental design was completely randomized, with three replication. The plants collect times studied were eight, seven and six, starting at 21 days after emergence of seedlings (DAE). The evaluations were done at each collecting time. The cultivation conditions affected the crop cycle of the black oat, causing considerable differences among experiments in the values of leaf area index, leaf area duration and total dry matter, with reflexes in the relative growth rate and in the crop grow rate. The three experiments presented similarities in the curves physiologic parameters standards during the plants development, although cultivation conditions differences.

Key words: Avena strigosa, growth, crop cycle.

\section{INTRODUÇÃO}

A aveia preta tem sido destinada à alimentação animal como pastejo direto, feno e silagem e, ao manejo e conservação do solo como cobertura verde. Também é de fundamental importância para ser utilizada, como alternativa de inverno, em sistema de rotação de culturas (Santos, 1991).

As variações na produção de matéria seca e no valor nutritivo, obser- 
vadas por diversos autores, podem ser explicadas pelas condições ambientais $e$ de manejo, nas quais os experimentos foram conduzidos (Fontaneli $e t a l$, 1987; Costa \& Martinez, 1988). Os resultados destes trabalhos mostram que as espécies de aveia apresentam maiores rendimentos de matéria seca quando colhidas a partir de 60 dias de crescimento (Vilela et al., 1982). Para Souto et al. (1992), a concentração de raízes de plantas de aveia não pode ser associada às características químicas do solo, porém, os espaçamentos e as densidades populacionais não interferem na distribuição do sistema radicular e o peso de matéria seca da parte aérea das plantas.

Magalhães (1986) relata que a análise de crescimento é um método que pode ser utilizado para pesquisa do efeito dos fenômenos ecológicos sobre o crescimento, como adaptabilidade das espécies em ecossistemas diversos, efeitos de competição, diferenças genotípicas da capacidade produtiva e influência das práticas agronômicas sobre o crescimento. Assim, a análise de crescimento descreve as condições morfofisiológicas da planta, em diferentes intervalos de tempo, permitindo acompanhar a dinâmica da produtividade. Também afirma que a determinação da área foliar é importante, porque as folhas são as principais responsáveis pela captação de energia solar e pela produção de matéria orgânica, através da fotossíntese. Se a superfície foliar é conhecida e a alteração do peso da planta, durante certo período de tempo, é calculada, torna-se possível avaliar a eficiência das folhas e a sua contribuição para o crescimento da planta como um todo.

O objetivo do presente trabalho foi estudar o comportamento fisiológico de plantas de aveia preta, cultivar Comum, submetidas a diferentes condições de cultivo, através da análise de crescimento, nos anos de 1986 e 1987, em Botucatu-SP.

\section{MATERIAL E MÉTODOS}

Foram conduzidos três experimentos (E1, E2 e E3) com aveiapreta (Avena strigosa Schreb) cv. Comum, em condições de campo, em solo classificado como Terra Roxa Estrutura distrófica, textura argilosa (Carvalho et al., 1983) (E1 e E3) e, em solo classificado como Solo 
Litólito, substrato basalto (Carvalho et al., 1983) (E2), pertencentes à Fazenda Experimental Lageado (FEL) da UNESP, localizada no município de Botucatu, SP, com altitude de $815 \mathrm{~m}$, latitude de $22^{\circ} 51^{\prime} \mathrm{S}$ e longitude de 48²6'WGrw, nos anos de 1986 (E1 e E2) e 1987 (E3).

O delineamento experimental utilizado foi inteiramente casualizado, com três repetições. Os tratamentos, em número de 8,7 e 6, constaram de épocas de coletas de plantas, iniciadas aos 21 dias após a emergência das plântulas, com intervalos de 21 dias, respectivamente para E1 (30/06/86; 21/07/86; 11/08/86; 01/09/86; 22/09/86; 13/10/86; 03/11/86; 24/11/86), para E2 (26/06/86; 17/07/86; 07/08/86; 28/08/86; $18 / 09 / 86 ; 09 / 10 / 86 ; 30 / 10 / 86)$ e para E3 $(8 / 06 / 87 ; 29 / 06 / 87 ; 20 / 07 / 87$; $10 / 08 / 87 ; 31 / 08 / 87 ; 21 / 09 / 87)$.

As adubações realizadas na semeadura em área total, foram feitas com base nas recomendações encontradas nas Instruções Agrícolas para o Estado de São Paulo (Instituto Agronômico, 1986), para aveia (Avena sativa $\mathrm{L}$ ), com $10 \mathrm{~kg} / \mathrm{ha}$ de $\mathrm{N}, 60 \mathrm{~kg} / \mathrm{ha}$ de $\mathrm{P}_{2} \mathrm{O}_{5}$ e $40 \mathrm{~kg} / \mathrm{ha}$ de $\mathrm{K}_{2} \mathrm{O}$, nas formas de sulfato de amônio, superfosfato simples e cloreto de potássio, respectivamente.

As semeaduras, realizadas manualmente, em 30/05/86 (E1), 26/ 05/86 (E2) e 07/05/87 (E3), tiveram a densidade de 60, 50 e 30 sementes por metro linear, respectivamente, para os experimentos E1, E2 e E3, com espaçamento entre linhas de $0,20 \mathrm{~m}$. As emergências das plântulas foram constatadas aos 10/06/86 (E1), 06/06/86 (E2) e 18/05/87 (E3). Os tratos culturais constaram de capinas e adubação de cobertura com 30 $\mathrm{kg} / \mathrm{ha}$ de nitrogênio na forma de sulfato de amônio realizados em torno de 20 a 30 dias após a semeadura.

Para cada experimento, em cada época de colheita, foram coletadas as plantas de $0,5 \mathrm{~m}$ em linha contínua de cada repetição. Elas foram levadas para o laboratório, acondicionadas em sacos de papel, para avaliação dos índices de área foliar, empregando-se o medidor de área foliar (Automatic Area Meter), Modelo AAM7, Marca Hayashi-Denkoh Co. Ltd, Tóquio, Japão, o qual mede a área foliar em centímetros quadrados. Em seguida, estas plantas foram submetidas a secagem em estufa para determinação da matéria seca das raízes, das hastes, do limbo e das bai- 
thas das folhas, das sementes e das raques das panículas e, matéria seca total, todos em $\mathrm{g} / \mathrm{m}^{2}$.

Obtidos os dados de área foliar (AF) e de matéria seca das plantas (MST), foram estimados os índices fisiológicos, a partir de equações com base em Radford (1967) e Portes \& Castro Jr. (1991).

A razão de área foliar (RAF) fornece uma estimativa do aparelho assimilador, sendo definida como o quociente entre a AF e a MST, em centímetros quadrados por grama $\left(\mathrm{cm}^{2} / \mathrm{g}\right)$, enquanto a taxa assimilatória líquida (TAL) reflete a eficiência deste sistema, em termos de matéria seca produzida em gramas, por centímetro quadrado de área foliar, na unidade de tempo $\left(\mathrm{g} / \mathrm{cm}^{2}\right.$.dia), definidas pelas equações:

$$
\begin{gathered}
\mathrm{RAF}=\frac{\mathrm{AF}}{\mathrm{MST}} \\
\mathrm{TAL}_{\mathrm{n} \rightarrow \mathrm{n}-1}=\frac{\left(\mathrm{MST}_{\mathrm{n}}-\mathrm{MST}_{\mathrm{n}-1}\right)}{\left(\mathrm{AF}_{\mathrm{n}}-\mathrm{AF}_{\mathrm{n}-1}\right)} \times \frac{\left(\mathrm{LAF}_{\mathrm{n}}-\mathrm{LAF}_{\mathrm{n}-1}\right)}{\left(\mathrm{t}_{\mathrm{n}}-\mathrm{t}_{\mathrm{n}-1}\right)},
\end{gathered}
$$

onde $\mathrm{L}=$ logaritmo natural, $\underline{\mathrm{t}}=$ intervalo entre coletas (dias) e $\underline{\mathrm{n}}=$ número de ordem de coleta.

A taxa de crescimento relativo (TCR), em gramas por grama e por dia (g/g.dia), corresponde ao incremento da MST, por unidade de MST existente, na unidade de tempo:

$$
\operatorname{TCR}_{n \rightarrow n-1}=\frac{\left(\operatorname{LMST}_{n}-\operatorname{LMST}_{n-1}\right)}{\left(t_{n}-t_{n-1}\right)} .
$$

A taxa de crescimento da cultura (TCC), em gramas por metro quadrado e por dia $\left(\mathrm{g} / \mathrm{m}^{2}\right.$.dia), equivale à variação ou incremento de material da planta entre duas amostragens, por unidade de tempo. É um indice fisiológico que indica a velocidade média de crescimento ao longo do período de observação:

$$
\operatorname{TCC}_{n \rightarrow n-1}=\frac{\left(\operatorname{MST}_{n}-\operatorname{MST}_{n-1}\right)}{\left(t_{n}-t_{n-1}\right)}
$$


A área foliar específica (AFE), em centímetros quadrados por grama $\left(\mathrm{cm}^{2} / \mathrm{g}\right)$, corresponde à razão entre a área das folhas $(\mathrm{AF})$ e a sua matéria seca (MS):

$$
\mathrm{AFE}=\frac{\mathrm{AF}}{\mathrm{MSF}},
$$

A razão de massa foliar (RMF), em grama por grama (g/g), é o quociente entre a MSF e a MST:

$$
\mathrm{RMF}=\frac{\mathrm{MSF}}{\mathrm{MST}}
$$

A razão de massa das raízes (RMR), em grama por grama (g/g), é o quociente entre a matéria seca das raízes (MSR) e a MST:

$$
\mathrm{RMR}=\frac{\mathrm{MSR}}{\mathrm{MST}},
$$

A razão de massa das sementes (RMS), em grama por grama $(\mathrm{g} / \mathrm{g})$, é o quociente entre a matéria seca das sementes (MSS) e a MST:

$$
\text { RMS }=\frac{\text { MSS }}{\text { MST }}
$$

Os parâmetros de matéria seca total e de índice de área foliar foram ajustados ao modelo exponencial polinomial de $2^{\circ}$ grau, com base em Portes \& Castro Jr. (1991). No caso dos parâmetros fisiológicos (TCC, TCR, TAL e DAF), foram apresentadas as médias de tratamento em cada coleta e a representação gráfica das mesmas.

Para que a análise estatística fosse realizada, foi primeiramente, realizado o teste para verificar se os erros apresentavam variâncias razoavelmente homogêneas (Zimmermann, 1987). Quando as variâncias dos erros foram muito heterogêneas, caracterizando a heterocedastícia, foi realizada a transformação dos dados. Neste trabalho, mesmo após a trans- 
formação dos dados, os erros das variáveis AFE e RAF, do experimento E1 e os das variáveis IAF, AFE E RAF, do experimento E2, continuaram apresentando variâncias excessivamente heterogêneas, não sendo realizada a análise da variância destas variáveis. Nas tabelas encontram-se os dados originais. As médias foram comparadas pelo teste de Tukey, a 5\% de probabilidade.

\section{RESULTADOS E DISCUSSÃO}

O número médio de plantas $/ \mathrm{m}^{2}$ não apresentou diferenças significativas no decorrer das coletas, obtendo-se na média destas 256,7 plantas $/ \mathrm{m}^{2}, 208,1$ plantas $/ \mathrm{m}^{2}$ e 125,6 plantas $/ \mathrm{m}^{2}$, para os experimentos E1, E2 e E3, respectivamente; obtendo-se portanto três populações distintas de plantas nos três experimentos.

Pela Tabela 1, constata-se o máximo de índice área foliar (IAF) nas plantas de aveia preta do experimento E1, aos 84 dias após a emergência (DAE), ocasião em que foi observada a emissão de panículas. No entanto, não houve diferença estatística em relação aos 105. Para o experimento E3 (Figura 1), em que o ciclo foi menor, o máximo valor foi observado aos 63 DAE; embora não tenha sido observada diferença significativa entre 42 a 105 DAE. Para os três experimentos, constata-se diminuição dos valores de área foliar a partir da quinta coleta (105 DAE), em virtude das plantas encontrarem-se na fase final de seu desenvolvimento vegetativo, com senescência e perdas de folhas e havendo desvio de assimilados para sustentar a formação de sementes. Em aveia e outros cereais, o IAF caracteriza-se por apresentar um pico entre períodos de rápido aumento e rápido declínio (Brouwer \& Flood, 1995), bem caracterizado neste trabalho, principalmente no experimento E3. Comparando os três experimentos, o maior IAF foi obtido no E3, que apresentava menor população de plantas, mas com maior número de perfilhos e $\mathrm{d} \epsilon$ folhas, e o menor foi no E1, com maior população de plantas, mas com menor número de perfilhos e folhas.

Os valores máximos de acúmulo da matéria seca total durante $o$ desenvolvimento das plantas de aveia preta ocorreram aos 168, 147 e 
Tabela 1. Dados médios de índice de área foliar (IAF), matéria seca total (MST), de plantas de aveia preta cultivadas nos anos de 1986 (E1 e E2) e de 1987 (E3). Botucatu, SP.

\begin{tabular}{ccc}
\hline Dias após a emergência (DAE) & IAF & MST $\left(\mathrm{g} / \mathrm{m}^{2}\right)$ \\
\hline 21 & Experimento E1 & $21,93 \mathrm{c}$ \\
42 & $0,26 \mathrm{de}$ & $47,53 \mathrm{bc}$ \\
63 & $0,59 \mathrm{cde}$ & $161,40 \mathrm{abc}$ \\
84 & $1,22 \mathrm{~cd}$ & $370,46 \mathrm{ab}$ \\
105 & $3,45 \mathrm{a}$ & $583,66 \mathrm{a}$ \\
126 & $2,61 \mathrm{ab}$ & $990,73 \mathrm{a}$ \\
147 & $1,63 \mathrm{bc}$ & $864,70 \mathrm{a}$ \\
168 & $0,01 \mathrm{e}$ & $1113,46 \mathrm{a}$ \\
$\mathrm{CV}$ & $0,02 \mathrm{e}$ & 4,77 \\
\hline & $32,90 \%$ & \\
21 & Experimento E2 & $64,10 \mathrm{c}$ \\
42 & 0,83 & $258,63 \mathrm{c}$ \\
63 & 1,81 & $553,46 \mathrm{bc}$ \\
84 & 3,31 & $911,20 \mathrm{ab}$ \\
105 & 4,81 & $1178,00 \mathrm{a}$ \\
126 & 2,42 & $1298,33 \mathrm{a}$ \\
147 & 1,10 & $1348,76 \mathrm{a}$ \\
$\mathrm{CV}$ & 0,01 & $26,95 \%$ \\
\hline & & $21,79 \mathrm{~d}$ \\
21 & Experimento E3 & $274,97 \mathrm{c}$ \\
42 & $0,36 \mathrm{~b}$ & $827,38 \mathrm{~b}$ \\
63 & $4,84 \mathrm{ab}$ & $1162,93 \mathrm{ab}$ \\
84 & $10,04 \mathrm{a}$ & $2085,57 \mathrm{a}$ \\
105 & $6,62 \mathrm{ab}$ & $1668,77 \mathrm{ab}$ \\
126 & $3,14 \mathrm{ab}$ & $4,35 \%$ \\
$\mathrm{CV}$ & $0,12 \mathrm{~b}$ & \\
\hline & $20,59 \%$ & 9 \\
\hline
\end{tabular}

Médias seguidas das mesmas letras não diferem entre si a 5\% de probabilidade, pelo teste de Tukey.

126 DAE (Tabela 1 e Figura 2), respectivamente, para os experimentos E1, E2 e E3, embora não tenham sido constatadas algumas diferenças significativas. Como a partir do $105 \mathrm{DAE}$, houve senescência e queda de folhas, leva-se a inferir que a partir da emissão das panículas, observada aos 84 dias, a maior contribuição na produção de matéria seca total foi devido à matéria seca das hastes e das sementes. Constata-se ainda que os menores valores acumulados foram encontrados nas plantas do E1, com maior população de plantas, mas com menor número de perfilhos. Comparando-se os três experimentos, verifica-se um encurtamento do 
ciclo cultural, com menor período para as plantas do $\mathrm{E} 3$ em relação às do E2, que por sua vez, em relação às do E1, face às condições climáticas terem sido mais favoráveis para E3 (Figuras 9 e 10), caracterizando o início de maio como tendo sido a melhor época de semeadura. Estes resultados estão de acordo com os trabalhos de Vilela et al. (1982), Fontaneli et al. (1987) e Rossetto \& Nakagawa (1995), que observaram variações na produção de matéria seca em função de diferenças no período vegetativo das plantas em decorrência das condições ambientais. No presente trabalho, observa-se que para os experimentos E1 e E2 (1986), na fase inicial de desenvolvimento, quando são formados os perfilhos primários, houve baixa precipitação pluvial (Figura 9), o que deve ter contribuído para diminuição destes e, conseqüentemente, na produção de matéria seca das hastes, em relação ao experimento E3 (1987), onde as chuvas foram mais intensas no início da cultura (Figura 10). Observando-se os dados de IAF e de matéria seca total (Tabela 1 e Figura 1) dos três experimentos, constata-se que aos experimentos, com maiores valores de IAF, corresponderam aos maiores acúmulos de matéria seca.

Pela Figura 3, constata-se que a máxima taxa de crescimento da cultura (TCC), em $\mathrm{g} / \mathrm{m}^{2}$.dia, das plantas de aveia preta dos experimentos E2 e E3 ocorreu aos 84 DAE, na fase de emissão de panícula, e aos 105 dias para E1. Para os dois experimentos E2 e E3, constata-se decréscimo dos valores da TCC a partir da quinta coleta (105 DAE), enquanto para E1, a partir de 126 dias, à semelhança do observado para o índice de área foliar e como reflexo deste (Magalhães, 1985). Na avaliação do decréscimo iriais tardio dos valores da TCC em E1, deve-se salientar que foi no experimento com maior competição (60 sementes $/ \mathrm{m}$. linear). De acordo com Brown (1984), os valores máximos de TCC, geralmente, coincidem com os primeiros estádios de frutificação, seguindo-se de decréscimo com a maturação das plantas devido à paralisação do crescimento vegetativo, perda de folhas e senescência. Os maiores valores de TCC foram obtidos no experimento E3, que apresentou maior IAF (Tabela 1).

A taxa de crescimento relativo (TCR), em g/g.dia, tem seus valores apresentados na Figura 4. De acordo com Benincasa (1988), a TCR 

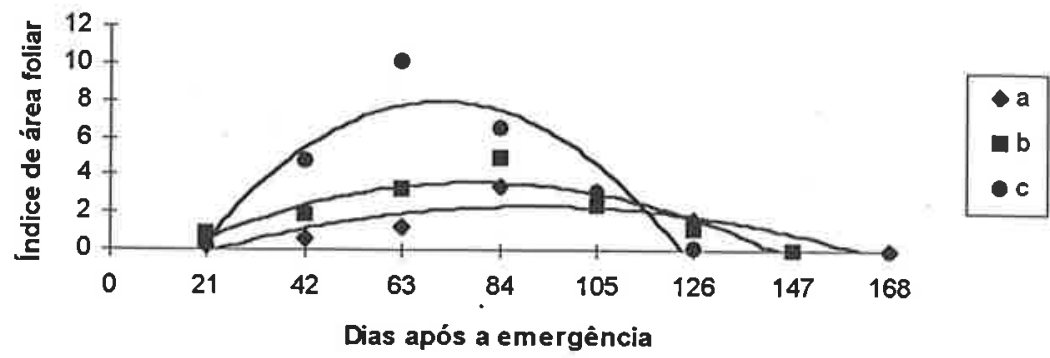

(a) $\mathrm{y}=(0.0226) * \operatorname{EXP}\left((0.1175) * \mathrm{x}+(-0.0007305) * \mathrm{x}^{\wedge} 2\right) \mathrm{R}^{2}=0.8829 *$ (b) $\mathrm{y}=(0.0498) * \operatorname{EXP}\left((0.1334) * \mathrm{x}+(-0.0009300)^{*} \mathrm{x}^{\wedge} 2\right) \mathrm{R}^{2}=0.9504 * *$ (c) $\mathrm{y}=(0.0111) * \operatorname{EXP}\left((0.1992) * \mathrm{x}+(-0.0014225) * \mathrm{x}^{\wedge} 2\right) \mathrm{R}^{2}=0.9891 * *$

Figura 1. Índice de área foliar das plantas de aveia preta cultivadas nos anos de 1986 (a e b) e de 1987 (c). Botucatu, SP.

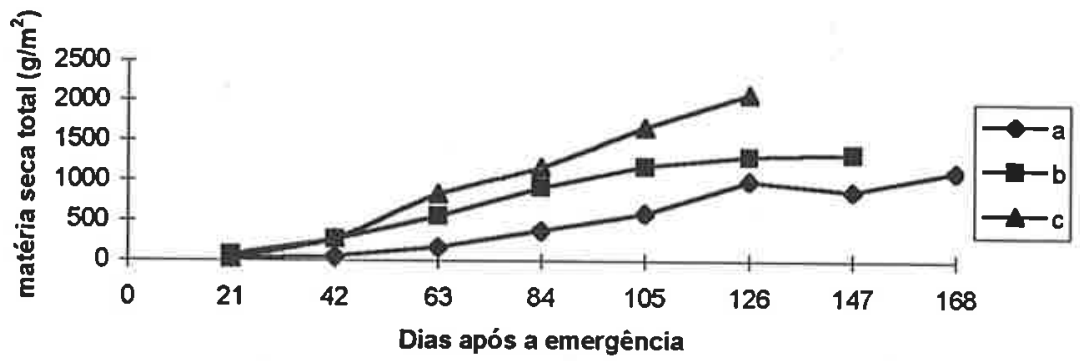

(a) $\mathrm{y}=(5.0849) * \operatorname{EXP}\left((0.0680)^{*} \mathrm{x}+(-0.000216) * \mathrm{x}^{\wedge} 2\right) \mathrm{R}^{2}=0.9953 * *$ (b) $\mathrm{y}=(18.855) * \operatorname{EXP}\left((0.0700) * \mathrm{x}+(-0.000287)^{*} \mathrm{x}^{\wedge} 2\right) \mathrm{R}^{2}=0.9947 * *$ (c) $\mathrm{y}=(2.6667) * \operatorname{EXP}\left((0.1252) * \mathrm{x}+(-0.0005879) * \mathrm{x}^{\wedge} 2\right) \mathrm{R}^{2}=0.9840 * *$

Figura 2. Matéria seca total $\left(\mathrm{g} / \mathrm{m}^{2}\right)$ das plantas de aveia preta cultivadas nos anos de 1986 (a e b) e de 1987 (c). Botucatu, SP. 
reflete o aumento da matéria seca de uma planta ou de qualquer órgão, num intervalo de tempo, sendo portanto, função de material pré - existente, ou seja, do tamanho inicial. A observação da Figura 4, mostra que houve redução constante desse parâmetro fisiológico desde o primeiro intervalo, tornando inclusive negativo na última coleta para todos os experimentos, como obtido para TCC (Figura 3) em função da planta encontrar-se em fase de senescência, com queda ou morte de folhas. De acordo com Rodrigues (1982), em soja, as TCR assemelham-se em seu comportamento geral, observando-se valores altos no primeiro intervalo, com posteriores decréscimos nos intervalos subseqüentes. Estes decréscimos ocorrem porque o aumento da matéria seca da planta é parte devido ao aumento da parte estrutural que não contribui para o crescimento, por não ser tecido metabolicamente ativo; o decréscimo é também parte em função do sombreamento e do aumento da idade das folhas da base da planta (Brown, 1984). Neste trabalho, os decréscimos do TCR foram maiores no experimento $\mathrm{E} 3$, com maior produção de matéria seca total (Tabela 1) e com menor ciclo cultural, e menores no experimento E1, com menor produção de matéria seca e maior ciclo cultural. No experimento E3, como comentado anteriormente, as condições climáticas (Figura 10) foram mais favoráveis, principalmente no início do desenvolvimento possibilitando maior TCC que a dos demais experimentos (Figura 3), porém um decréscimo mais acentuado da TCR em função deste maior desenvolvimento na fase inicial (Figura 4). Cabe salientar que, a densidade de semeadura em E3 foi metade da usada no experimento E1, portanto houve uma competição bem menor entre as plantas. Leite et al. (1999) comentam trabalhos, nos quais o decréscimo da TCR tem sido relacionado à redução do $\mathrm{IAF}$, sendo que com a idade pode ser o resultado do aumento dos tecidos não assimilatórios.

Os resultados obtidos para taxa assimilatória líquida (TAL), em $\mathrm{g} / \mathrm{cm}^{2}$.dia, para os três experimentos, encontram-se na Figura 5, onde foi verificado decréscimo da TAL, a partir de $147 \mathrm{DAE}$, para o E1 e, a partir de $105 \mathrm{DAE}$, para o E3. Deste modo, observa-se que ocorreram decréscimos da taxa assimilatória líquida, na fase final de vida das plantas. $\mathrm{Na}$ literatura, existe certa controvérsia entre os estudos sobre a TAL. Alguns 


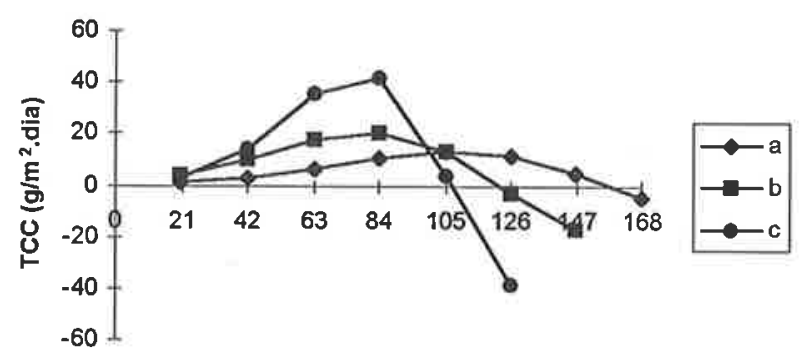

Dias após a emergência

Figura3. Taxa de crescimento da cultura TCC $\left(\mathrm{g} / \mathrm{m}^{2}\right.$.dia) das plantas de aveia preta cultivadas nos anos de 1986 (a e b) e de 1987 (c). Botucatu, SP.

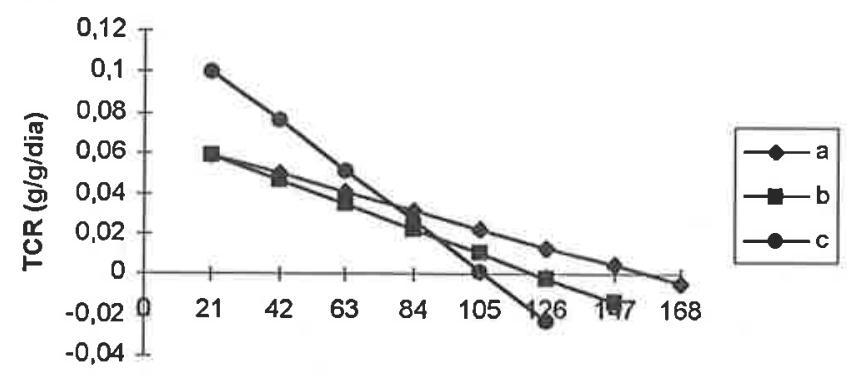

Dias após a emergência

Figura 4. Taxa de crescimento relativo TCR (g/g.dia) das plantas de aveia preta cultivadas nos anos de 1986 (a e b) e de 1987 (c). Botucatu, SP.

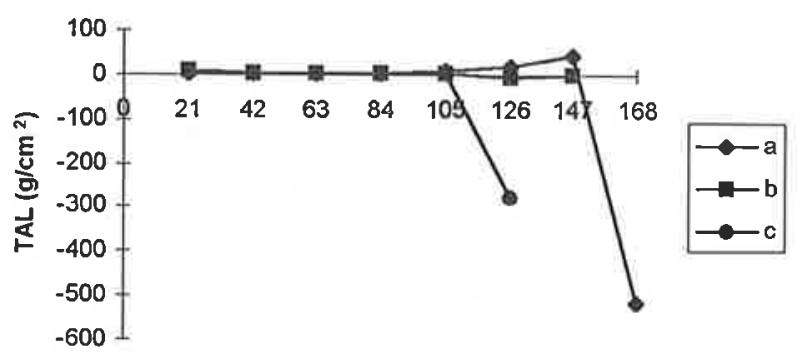

Dias após a emergência

Figura 5 Taxa assimilatória líquida TAL $\left(\mathrm{g} / \mathrm{cm}^{2}\right.$.dia) das plantas de aveia preta cultivadas nos anos de 1986 (a e b) e de 1987 (c). Botucatu, SP. 
autores reportam aumentos da taxa até uma determinada idade da planta, enquanto que para outros, não há variações durante o desenvolvimento da planta da mesma espécie. Rodrigues (1992), em soja, relatou que a TAL diminuía com a idade da planta. Tais divergências, talvez sejam devidas à influência de condições climáticas, forma de condução dos experimentos e pelas variações intra-específicas desta taxa (Rosa, 1993), assim como da espécie da planta estudada, dos diferentes locais que foram desenvolvidos os experimentos, onde alguns poderiam apresentar um microclima mais favorável que outro. Brown (1984), por sua vez, comenta que o cálculo do TAL, considerando a área foliar, apresenta desvantagens por não estimar a verdadeira eficiência das folhas de diferentes idades e não levar em conta a fotossíntese realizada por outras partes verdes da planta. Em aveia, a eficiência fotossintética na panícula foi maior por unidade de área que nos tecidos de outros órgãos (Jennings \& Shibles, 1968).

Pela Tabela 2, verifica-se máxima razão de área foliar (RAF), em $\mathrm{cm}^{2} / \mathrm{g}$, para os experimentos E1 e E3, na segunda coleta (42 DAE) e na primeira para E2, decrescendo até a sexta coleta (126 DAE). Assim, constata-se, nestes experimentos, queda neste índice fisiológico, à medida que a planta se desenvolve, pois a potencialidade de produção de assimilação decresce, tendo sido mais intensa a partir da quarta coleta (84 DAE), quando da emissão das panículas (Figura 6). De acordo com Rodrigues (1982), a RAF é uma medida relativa do aparelho assimilador. No experimento E3, a RAF foi maior, nas primeiras coletas por ter apresentado maiores valores de AFE (Tabela 2) e RMF (Tabela 3) nestas coletas. Estes valores da RAF devem ter ainda contribuido efetivamente para os altos valores iniciais de TCR observados para E3 (Figura 4), anteriormente comentado, por ter sido pequena diferença da TAL entre os três experimentos, tendo em vista as considerações encontradas em Magalhães (1984).

Para os três experimentos, houve aumento da duração de área foliar (DAF), em $\mathrm{cm}^{2} / \mathrm{cm}^{2}$.dia, da primeira para a terceira coleta (63 DAE) (Figura 7). Para os experimentos E1 e E3, a DAF continuou aumentando durante todo o ciclo, com menor intensidade após a emissão das panículas 
Tabela 2. Dados médios de razão de área foliar (RAF) e área foliar específica (AFE) de plantas de aveia preta cultivadas nos anos de 1986 (E1 e E2) e de 1987 (E3). Botucatu, SP.

\begin{tabular}{cll}
\hline & Dias após a emergência (DAE) & AFE $\left(\mathrm{cm}^{2} / \mathrm{g}\right)$ \\
\hline & Experimento E1 & \\
21 & 0,011856 & 0,018479 \\
42 & 0,012624 & 0,022059 \\
63 & 0,007621 & 0,019049 \\
84 & 0,009339 & 0,028298 \\
105 & 0,004472 & 0,016645 \\
126 & 0,001645 & 0,009965 \\
147 & 0,000012 & 0,000082 \\
168 & 0,000018 & 0,000146 \\
$\mathrm{CV}$ & & \\
\hline & Experimento E2 & \\
21 & 0,013105 & 0,025301 \\
42 & 0,007269 & 0,020614 \\
63 & 0,005980 & 0,022502 \\
84 & 0,005345 & 0,029817 \\
105 & 0,005054 & 0,012650 \\
126 & 0,000847 & 0,006444 \\
147 & 0,000015 & 0,000133 \\
$\mathrm{CV}$ & & \\
\hline & & \\
21 & Experimento E3 & $0,026967 \mathrm{ab}$ \\
42 & $0,016980 \mathrm{ab}$ & $0,033294 \mathrm{a}$ \\
63 & $0,017602 \mathrm{a}$ & $0,029018 \mathrm{ab}$ \\
84 & $0,012147 \mathrm{ab}$ & $0,022374 \mathrm{~b}$ \\
105 & $0,005701 \mathrm{bc}$ & $0,008884 \mathrm{c}$ \\
126 & $0,001506 \mathrm{~b}$ & $5,71 \%$ \\
$\mathrm{CV}$ & $0,000072 \mathrm{c}$ & \\
\hline
\end{tabular}

Médias seguidas das mesmas letras, nas colunas, não diferem entre si a 5\% de probabilidade, pelo teste de Tukey.

(84 DAE), no entanto, para o E2, houve queda da DAF, a partir de 63 DAE. Os valores da DAF no experimento E3 com menor população de plantas foram superiores aos dos dois outros, provavelmente pela menor concorrência entre plantas, possibilitando a manutenção das folhas metabolicamente ativas por mais tempo, o que resultou na maior produção de matéria seca total (Tabela 1). Ehlers (1991) mostrou a importância da DAF, particularmente da folha bandeira, na produção de grãos de aveia. Analisando-se a Tabela 2, observa-se que para o experimento E3, houve aumento da área foliar específica (AFE), em $\mathrm{cm}^{2} / \mathrm{g}$, da primeira 
(21 DAE) para a segunda coleta, como decorrência de alteração morfológica nas folhas, através de aumento na expansão foliar. De acordo com Radford (1967), a AFE representa as diferenças no espessamento foliar, ou seja, permite verificar se as plantas estão acumulando fotossimilados em suas folhas ou se estão translocando-os para outros órgãos. Para os experimentos E1 e E2, os valores de AFE tenderam a aumentar a partir da primeira até a quarta coleta (Tabela 2). Nos três experimentos observa-se que a AFE diminuiu de maneira acentuada dos 84 DAE até 105 DAE (Figura 8), indicando diminuição da área foliar e, ou, acúmulo de fotossintetizados nas folhas, correspondendo este ao período logo após da emissão das panículas, e com as sementes em início de formação. Após $105 \mathrm{DAE}$, os decréscimos foram menores em função da translocação de fotoassimilados das folhas e da senescência destas.

Pela Tabela 3 verifica-se redução da razão de massa foliar (RMF), em $\mathrm{g} / \mathrm{g}$, em todos os experimentos, da primeira até a quarta ou quinta coleta. Este comportamento ocorre porque no início do ciclo o aumento do número de folhas e o seu maior desenvolvimento anatômico ocasiona predominância da sua massa. À medida que a planta desenvolveu-se, foi menor a contribuição da folha na matéria seca total, particularmente após a emissão da panícula (84 dias), pois foi menor a fração de material retido na folha, havendo direcionamento de assimilados das folhas para os demais órgãos da planta. De acordo com Benincasa (1988), este componente da razão foliar é basicamente fisiológico, expressando a fração de matéria seca não exportada das folhas ao resto da planta.

No experimento E1 houve aumento da razão de massa de raiz (RMR),em g/g, da primeira para a terceira coleta. Já Para os E2 e E3, não houve diferença significativa entre as coletas. Além disso, pode-se constatar valores de RMR das últimas coletas semelhantes aos das coletas iniciais, para os três experimentos (Tabela 3). Os maiores valores de RMR obtidos para os experimentos E1 e E2 podem estar relacionados a menor precipitação pluvial observada na fase inicial destes experimentos (Figura 9), quando comparado com a do experimento E3 (Figura 10). Esta ocorrência resultou em maior proporção de matéria seca das raízes em relação à parte aérea. 
Tabela 3. Dados médios de razão de matéria seca de raiz, folha e semente (RMR, RMF, RMS) de plantas de aveia preta cultivadas nos anos de 1986 (E1 e E2) e de 1987 (E3). Botucatu, SP.

\begin{tabular}{|c|c|c|c|}
\hline Dias após a emergência (DAE) & $\mathrm{RMR}(\mathrm{g} / \mathrm{g})$ & $\operatorname{RMF}(\mathrm{g} / \mathrm{g})$ & RMS (g/g) \\
\hline \multicolumn{4}{|c|}{ Experimento El } \\
\hline 21 & $0,09 \mathrm{~b}$ & $0,64 \mathrm{a}$ & $0,00 \mathrm{~b}$ \\
\hline 42 & $0,17 \mathrm{~b}$ & $0,56 \mathrm{ab}$ & $0,00 \mathrm{~b}$ \\
\hline 63 & $0,33 \mathrm{a}$ & $0,40 \mathrm{abc}$ & $0,00 \mathrm{~b}$ \\
\hline 84 & $0,24 \mathrm{ab}$ & $0,33 \mathrm{bc}$ & $0,02 a b$ \\
\hline 105 & $0,12 \mathrm{~b}$ & $0,27 \mathrm{c}$ & $0,10 \mathrm{ab}$ \\
\hline \multirow{4}{*}{$\begin{array}{l}126 \\
147 \\
168\end{array}$} & $0,12 \mathrm{~b}$ & $0,16 \mathrm{c}$ & 0,23 a \\
\hline & $0,11 \mathrm{~b}$ & $0,14 \mathrm{c}$ & $0,25 \mathrm{a}$ \\
\hline & $0,13 \mathrm{~b}$ & $0,12 \mathrm{c}$ & $0,21 a b$ \\
\hline & $10,61 \%$ & $9,70 \%$ & $24,69 \%$ \\
\hline \multicolumn{4}{|c|}{ Experimento E2 } \\
\hline 21 & $0,29 \mathrm{a}$ & $0,52 \mathrm{a}$ & $0,00 \mathbf{a}$ \\
\hline 42 & $0,41 \mathrm{a}$ & $0,37 \mathrm{ab}$ & $0,00 \mathrm{a}$ \\
\hline 63 & $0,41 \mathrm{a}$ & $0,28 \mathrm{ab}$ & $0,00 \mathrm{a}$ \\
\hline 84 & $0,36 \mathrm{a}$ & $0,19 \mathrm{~b}$ & $0,05 \mathrm{a}$ \\
\hline 105 & $0,25 \mathrm{a}$ & $0,19 \mathrm{~b}$ & $0,10 \mathrm{a}$ \\
\hline 126 & $0,22 \mathrm{a}$ & $0,15 b$ & $0,10 \mathrm{a}$ \\
\hline 147 & $0,24 \mathrm{a}$ & $0,13 \mathrm{~b}$ & $0,07 \mathrm{a}$ \\
\hline $\mathrm{CV}$ & $15,45 \%$ & $12,62 \%$ & $29,69 \%$ \\
\hline \multicolumn{4}{|c|}{ Experimento E3 } \\
\hline 21 & $0,17 \mathrm{a}$ & $0,65 \mathrm{a}$ & $0,00 \mathrm{~b}$ \\
\hline 42 & $0,17 \mathrm{a}$ & $0,52 \mathrm{a}$ & $0,00 \mathrm{~b}$ \\
\hline 63 & $0,12 \mathrm{a}$ & $0,42 \mathrm{ab}$ & $0,00 \mathrm{~b}$ \\
\hline 84 & $0,12 \mathrm{a}$ & $0,25 \mathrm{bc}$ & $0,02 \mathrm{~b}$ \\
\hline 105 & $0,09 \mathrm{a}$ & $0,17 \mathrm{c}$ & $0,14 a b$ \\
\hline 126 & 0,13 a & $0,11 \mathrm{c}$ & $0,24 \mathrm{a}$ \\
\hline $\mathrm{CV}$ & $10,87 \%$ & $21,82 \%$ & $26,35 \%$ \\
\hline
\end{tabular}

Médias seguidas das mesmas letras, nas colunas, não diferem entre si a 5\% de probabilidade, pelo teste de Tukey.

Pela Tabela 3, verifica-se que a partir dos $84 \mathrm{DAE}$, para os três experimentos, os valores de razão de massa das sementes (RMS), em $\mathrm{g} / \mathrm{g}$, aumentaram em relação à coleta anterior. Para os experimentos E1 e E3, observa-se maior RMS aos $126 \mathrm{DAE}$; enquanto para E2, a análise estatística não acusou diferenças significativas. $\mathrm{O}$ valor menor da $\mathrm{RMS}$ da última coleta do experimento $\mathrm{E} 1$ deve ser o resultado do início de degrana, observado nas panículas principais. As diferenças nas RMS entre experimentos podem ser atribuídas as alterações de condições climáticas 


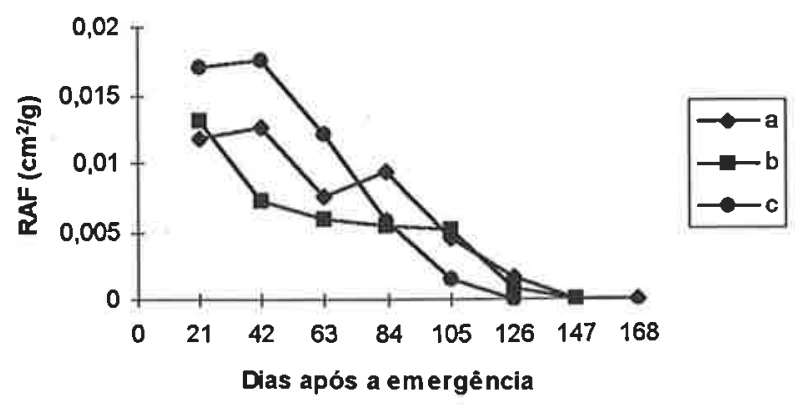

Figura 6. Razão de área foliar RAF $\left(\mathrm{cm}^{2} / \mathrm{g}\right)$ das plantas de aveia preta cultivadas nos anos de 1986 (a e b) e de 1987 (c). Botucatu, SP.

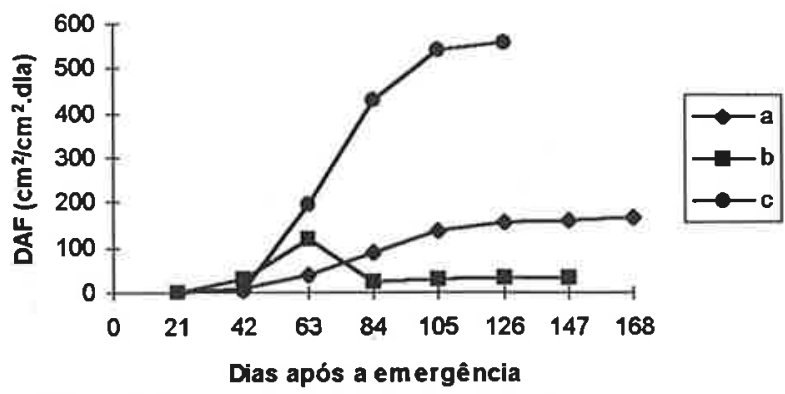

Figura 7. Duração de área foliar $\mathrm{DAF}\left(\mathrm{cm}^{2} / \mathrm{cm}^{2}\right.$.dia $)$ das plantas de aveia preta cultivadas nos anos de 1986 (a e b) e de 1987 (c). Botucatu, SP.
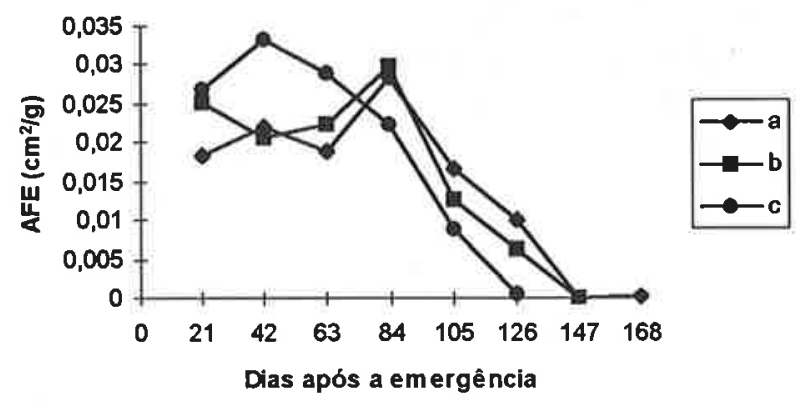

Figura 8. Área foliar específica AFE $\left(\mathrm{cm}^{2} / \mathrm{g}\right)$ das plantas de aveia preta cultivadas nos anos de 1986 (a e b) e de 1987 (c). Botucatu, SP. 


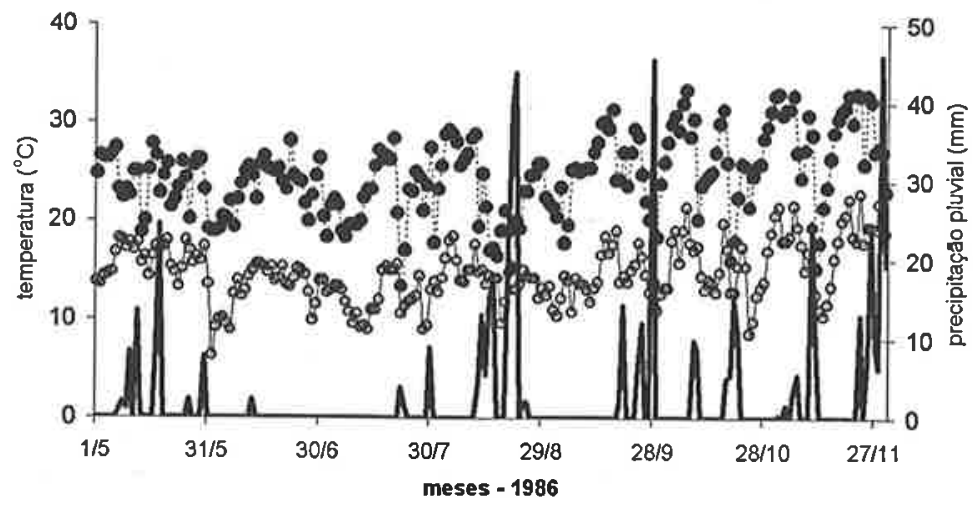

— @-temperatura minima $\cdot \cdots \cdot \cdots \cdot \cdot$ temperatura máxima —

Figura 9. Dados diários de precipitação pluvial e de temperaturas do ar máxima e mínima, no período de condução do experimento, em 1986.

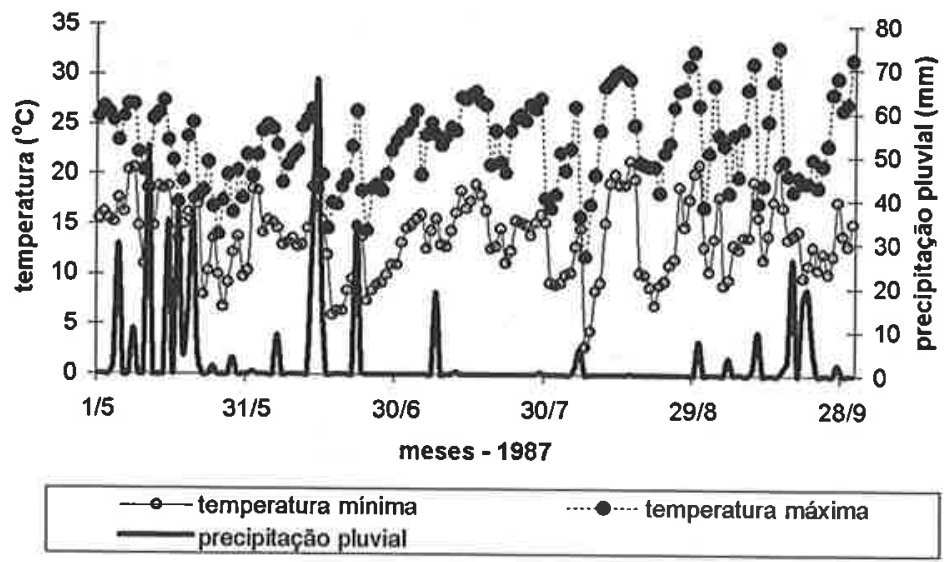

Figura 10. Dados diários de precipitação pluvial e de temperaturas do ar máxima e mínima, no período de condução do experimento, em 1987. 
que foram submetidas às plantas (Figuras $9 \mathrm{e} 10$ ), bem como as particularidades de condições de solo, de épocas de semeadura e de distintas populações de plantas. $\mathrm{O}$ efeito destes pode ser verificado tanto no acúmulo da matéria seca antes como após a formação das sementes (Tabela 1). Os assimilados das sementes são resultados da fotossíntese após a ântese e da remobilização de carboidratos armazenados em outras partes da planta anterior a ântese (Brouwer \& Flood, 1995). Este fato é bem ilustrado pela Tabela 3, na qual se observa que os valores de RMF e RMR decresceram à medida que aumentaram os valores de RMS, nos três experimentos.

\section{CONCLUSÕES}

1) As condições de cultivo afetaram o ciclo ontogenético da aveia preta, causando consideráveis diferenças entre experimentos nos valores de índice de área foliar, de duração de área foliar e de matéria seca total, com reflexos na taxa de crescimento relativo e na taxa de crescimento da cultura.

2) Os três experimentos apresentaram similaridades nos padrões das curvas dos parâmetros fisiológicos, no decorrer do desenvolvimento das plantas, apesar das diferenças de condições de cultivo.

\section{REFERÊNCIAS BIBLIOGRÁFICAS}

BENICASA, M.N.P. 1988. Análise de Crescimento de Plantas: Noções Básicas. Jaboticabal, FUNEP, 42p.

BROUWER, J.B. \& R.G. FLOOD, 1995. Aspects of Oat Physiology. In: WELCH, R.W. The Oat Crop. Production and Utilization. London: Chapman \& Hall, p.177-222.

BROWN, R.H. 1984. Growth of the Green Plant. In: TESAR, M.B. (ed.). Physiological Basis of the Crop Growth and Development. Madison: American Society of Agronomy \& Crop Science Society of America, 1984. p.153-174.

CARVALHO, W.A.; C.R. ESPINDOLA \& A.A. PACCOLA, 1983. Le- 
vantamento de Solos da Fazenda Lageado. Botucatu: Faculdade de Ciências Agronômicas, Campus de Botucatu/UNESP, 95p. (Boletim Técnico,1)

COSTA, C. \& H.E.P. MARTINEZ, 1988. Rendimento e Valor Protéico de Avena strigosa, Cultivada em Selviria, MS. Pesq. Agropec. Brasil., 23(6):653-657.

EHLERS, W. 1991. Leaf Area and Transpiration Efficiency During Different Growth Stages in Oats. J. of Agric. Sc., 116:183-190.

FONTANELI, R.S.; N.B. CUNHA \& M.F. RIBEIRO, 1987. Avaliação de Aveia Preta para Rendimento de Forragem e Grãos. In: REUNIÃO DA SOCIEDADE BRASILEIRA DE ZOOTECNIA, 24, 1987, Brasília, Anais ... Brasília: Sociedade Brasileira de Zootecnia, p.215.

INSTITUTO AGRONÔMICO. Instruções Agrícolas para o Estado de São Paulo, 3.ed., rev. atual. Campinas, 1986. (Boletim, 200). JENNINGS, V.M. \& R.M. SHIBLES. 1968. Genotypic Differences in Photosynthetic Contibutions of Plant Parts to Grain Yield in Oats. Crop Science, 8(2):173-175.

LEITE, M.L.; J.D.D RODRIGUES; M.M. MISCHAN \& J.S. VIRGENS FILHO. 1999. Efeitos do Défict Hídrico Sobre a Cultura do Caupi (Vigna unguiculata (L.) Walp), cv. EMBRAPA-821. II Análise de Crescimento. Rev. de Agricultura, 74(3):351-370.

MAGALHÃES, A.C.N., 1986. Análise Quantitativa de Crescimento. In: FERRI, M.G. Fisiologia Vegetal. São Paulo: EDUSP, 1:331-350. PORTES, T.A .\& L.G. CASTRO JUNIOR, 1991. Análise de Crescimento de Plantas: um Programa Computacional Auxilar. Rev. Bras. de Fisiol. Vegetal, 31(1):53-56.

RADFORD, P.S. 1967. Growth Analysis Formulae: Their Use and Abuse. Crop Sci., 7:171-175.

ROSA, C.A. Efeitos alelopáticos de (Brachiaria plantaginea (Link) Hitchcook) Sobre o Crescimento de Feijoeiro (Phaseolus vulgaris L. cv

Carioca). Botucatu: UNESP. 1993. 141p. (Dissertação de Mestrado). RODRIGUES, S.D. Análise de Crescimento de Plantas de Soja (Glycine max L. Merril) Submetidas à Carências Nutricionais. Rio Claro, 1982, 165p. (Dissertação de Mestrado). 
ROSSETTO, C.A.V.; NAKAGAWA, J., 1995. Efeito da Época de Semeadura na Produção e Qualidade de Sementes de Aveia Preta (Avena strigosa Schreb). Científica, 23(1):171-184.

SANTOS, H.P., 1991. Efeito de Sistemas de Cultivo sobre Rendimento de Grãos e Outras Características Agronômicas da Aveia Preta e da Branca, em Rotação com Trigo. Pesq. Agropec. Bras.,26(5):709-714. SOUTO, J.S; ISHI, T.; ROSOLEM, C.A.; CAVARIANI, C., 1992. Distribuição do Sistema Radicular de Aveia Preta em Função da População e Espaçamento. Pesq. Agropec. Bras., 27(9):1283-1289. VILELA, H.; GOMIDE, J.A.; MAESTRI, M., 1982. Crescimento e Interceptação de Luz e Vigor de Rebrota em População de Avena byzantina. Arquivos da Escola Veterinária/ UFMG, 34(1):185-191. ZIMMERMANN, F.J.P., 1987. Efeito da Heterogeneidade de Variância e Distribuição de Probabilidade dos Dados Sobre o Poder e Tamanho do Teste F. Pesq. Agropec. Bras., 22(1):209-1213. 